\title{
Metachronous pulmonary and adrenal metastases after liver transplantation for hepatocarcinoma
}

\author{
Shan-Wen Chen, Shuo Wang ${ }^{*}$, Bo Wang, Wei-Dong Li, Sheng Yan and Li-Ping Xie
}

\begin{abstract}
Background: The worldwide experience of surgical resection for isolated metastasis following liver transplantation (LT) for hepatocellular carcinoma (HCC) is limited.

Methods: The case of a 60-year-old patient performed successful surgical management for metachronous pulmonary and adrenal metastases from HCC after LT.

Results: Eighty months after $L T$, he was presently alive and disease-free with a normal AFP value.

Conclusion: The case is an interesting report on a somehow indolent metastatic spread of HCC after LT. It should be considered that metachronous metastatic resectable disease, with no data of recurrence at the primary site in an operable patient, is an indication to perform a surgical resection.
\end{abstract}

Keywords: liver transplantation, metachronous, metastasis, surgical management

\section{Background}

The worldwide experience of surgical resection for isolated metastasis following liver transplantation (LT) for hepatocellular carcinoma (HCC) is limited [1-3]. Here we reported a rare case of successful surgical management of metachronous pulmonary and adrenal metastases after LT for HCC. To our knowledge, successful managements for metachronous pulmonary and adrenal metastases from HCC after LT have not been previously reported in English literature.

\section{Case presentation}

A 60-year-old man, with a 20-year history of type B hepatitis and hepatic cirrhosis, presented with a solid large mass in the left lateral segment. The patient was poor-hepatic functional reserve because of atrophy of the right liver and compensative hyperplasia of the left liver according to imaging studies. The serum alphafetoprotein (AFP) value was 7,812.0 $\mathrm{ng} / \mathrm{ml}$, serum albumin level was $29.4 \mathrm{~g} / \mathrm{L}$, and other laboratory data were within normal limits. The Child-Pugh classification of the cirrhosis was Child early B cirrhosis. He underwent LT on 9 February 2004 and had received 3 cycles'

\footnotetext{
* Correspondence: csw123@sohu.com

Department of Urology, First Affiliated Hospital, Medical College of Zhejiang University, 79 Qingchun Road, Hangzhou, Zhejiang, 310031, P.R. China
}

postoperative adjuvant chemotherapy with capecitabine and oxaliplatin for 5 months. After LT, the AFP value decreased within a normal range and stayed normal for thirty months.

Thirty-three months after LT, a $3.0 \mathrm{~cm} \times 3.5 \mathrm{~cm}$ lesion was detected in the right lung with elevated AFP value $(167.1 \mathrm{ng} / \mathrm{ml})$. Because positron emission tomography (PET) scan revealed no fluorodeoxyglucose (FDG)-avid focus in transplanted liver and other extrahepatic organs, partial resection of the lower lobe of the right lung was performed. After pulmonary resection, the AFP value decreased within a normal range.

Thirty-nine months after LT, an abdominal computed tomography $(\mathrm{CT})$ scan revealed a $4.0 \mathrm{~cm} \times 3.5 \mathrm{~cm}$ homogeneous mass in the left adrenal gland with elevated AFP value $(55.8 \mathrm{ng} / \mathrm{ml})$ (Figure $1 \mathrm{~A})$. Furthermore, the PET scan revealed a FDG-avid enlarged left adrenal gland without FDG-avid activity in transplanted liver. Neither recurrent nor metastatic foci in any other organs was detectable after thorough examination, except for the left adrenal grand. Review of the older PET scan and other imaging studies showed no evidence of the adrenal lesion. The American Society of Anesthesiologists (ASA) grade of the patient was II grade. Based on the previous findings, a laparoscopic extraperitoneal adrenalectomy was performed on 13 May 2007. 


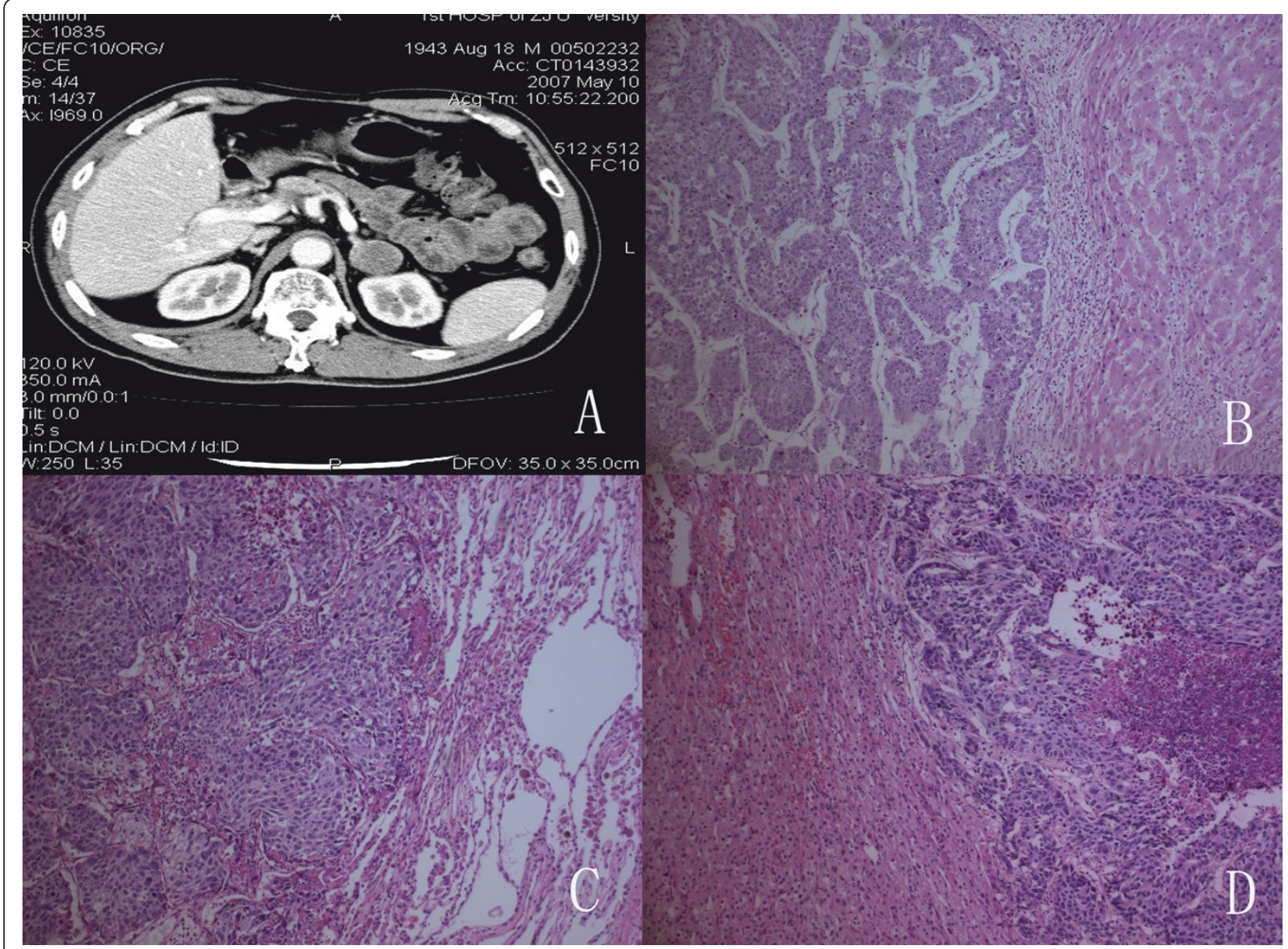

Figure 1 Enhanced abdominal computed tomography. A, Enhanced abdominal computed tomography revealed a homogeneous $4.0 \mathrm{~cm} \times 3.5$ $\mathrm{cm}$ mass in the left adrenal gland with no calcification. $B$, The histological findings of the hepatic tumor. $C$, The histological findings of the lung tumor.D, The histological findings of the adrenal tumor (H\&E, Stain $\times 400)$.

Postoperatively, the patient received 6 cycles' adjuvant chemotherapy with gemcitabine and 5 -fuorouracil. Three years after adrenalectomy, the patient is presently alive and disease-free with a normal AFP value. He is presently on tacrolimus and sirolimus for immunosuppression. The tumor metastases and therapeutic interventions related with the changes of the AFP levels could be seen in Figure 2.

\section{Histopathology}

The histopathology of the resected liver revealed a large tumor in the left lobe $(9 \mathrm{~cm} \times 8 \mathrm{~cm} \times 8 \mathrm{~cm})$ with features of poorly differentiated hepatocellular carcinoma. The uninvolved liver showed cirrhosis (Figure 1B). The tumors in the lung and adrenal were $3.0 \mathrm{~cm} \times 3.0 \mathrm{~cm} \times$ $3.5 \mathrm{~cm}$ and $3.0 \mathrm{~cm} \times 3.3 \mathrm{~cm} \times 4.0 \mathrm{~cm}$ in size, respectively. The histological findings of the lung tumor showed that cells with round nuclei proliferated in clusters, and mitoses were visible in many nuclei (Figure 1C). In the adrenal gland, well-defined oval cells or nuclei proliferated solidly, and necrotic tissue was visible in the cancerous lesion (Figure 1D). AFP-positive cells were identified by immunohistochemistry both in the lung and adrenal lesions.

\section{Discussion}

LT is claimed to cure HCC and the underlying cirrhosis simultaneously in selected patients. Nevertheless, a careful follow-up is needed in those cases due to the possibility of neoplastic recurrence, which could take place not only in the graft, but also in extrahepatic organs such as lung, adrenal glands, and bone [4]. The cumulative survival rates of $6,12,24$, and 36 months after the initial diagnosis of extrahepatic metastases were $44.1 \%$, $21.7 \%, 14.2 \%, 7.1 \%$, respectively. The median survival time was 4.9 months (range, 0-37 months) [5]. Extrahepatic metastasis is a common cause of deaths in patients after LT. Those patients, who usually have multiple 


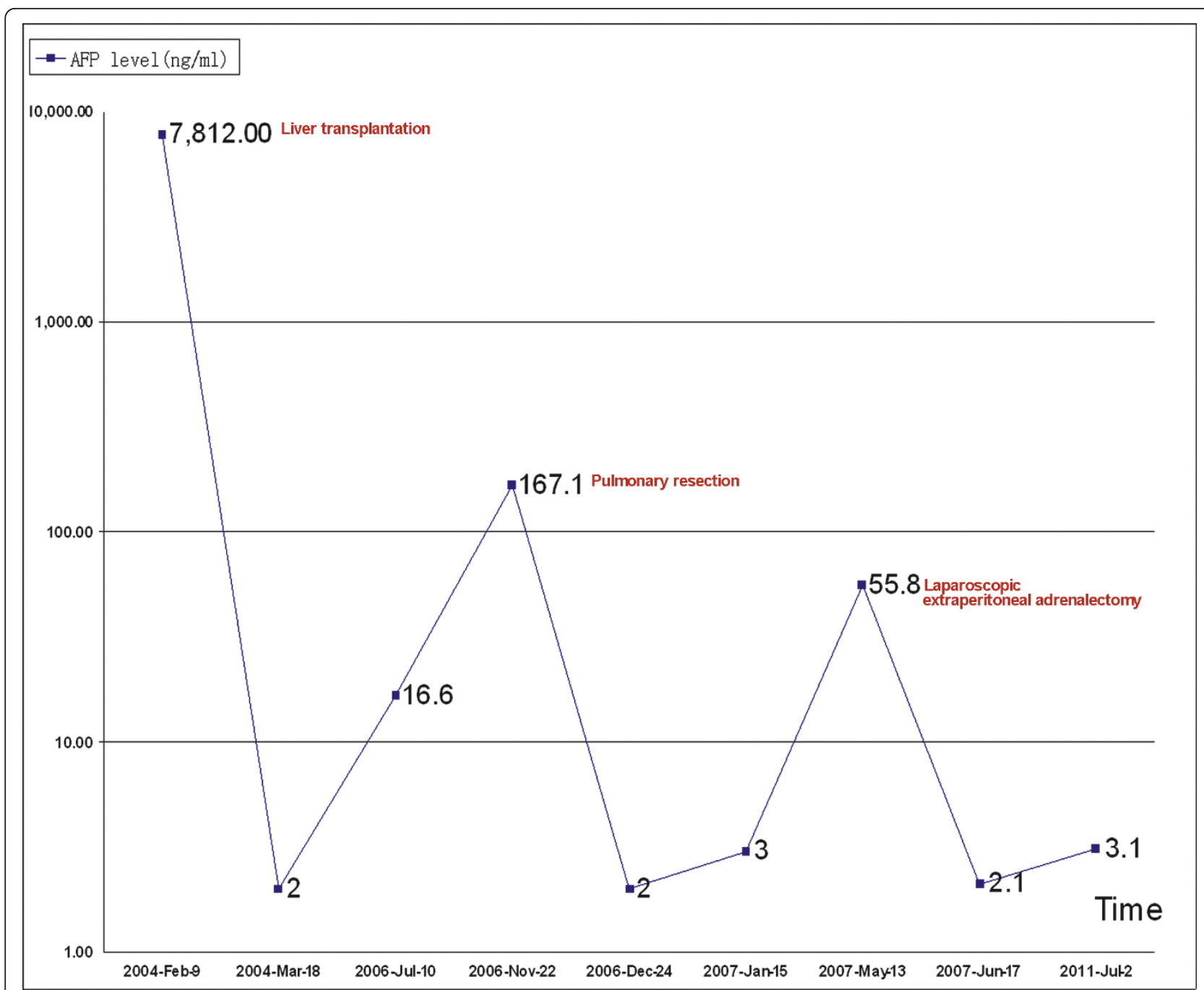

Figure 2 The patient's AFP level. The patient's AFP level was closely correlated to tumor metastases and therapeutic interventions.

metastases, could only be offered supportive care or palliative chemotherapy. However, previous studies showed that a solitary metastasis might have the opportunity of surgical resection $[1,6,7]$. In a report from Lyon, there were 7 patients who underwent adrenalectomy for metastatic $\mathrm{HCC}$, two died in the postoperative period in relation with pulmonary embolism $(\mathrm{n}=1)$ or acute pancreatitis $(n=1)$, and the mean survival time of the other five patients were 38 months after adrenalectomy [8].

The worldwide experience of surgical resection for isolated metastasis following LT for HCC is limited to case reports [1-3]. Rubio E et al reported one patient underwent adrenalectomy for the right adrenal metastasis 3 years after LT for HCC. The patient was alive when reported and disease-free for 24 months after adrenalectomy [1]. Herein, we have described a rare case of successful surgery for metachronous pulmonary and adrenal metastases after LT for HCC. Our patient had a unique character of metachronous metastasis instead of the systemic spread of cancer after operation. There were two metastatic sites: the lung and the adrenal gland; but each metastatic lesion was detectable only as a metachronous focus without any evidence of local recurrence or other extrahepatic metastasis. Furthermore, the patient's AFP level was closely corelated to tumor metastasis, which was a good indicator for tumor metastasis and made the surgical approach possible [9]. Palliative chemotherapy could be delivered to patients with recurrent $\mathrm{HCC}$ after LT with tolerable toxicity [10]. Capecitabine plus oxaliplatin regimen showed modest anti-tumour activity with tolerable toxicities in patients with advanced HCC $[11,12]$. Therefore, Capecitabine plus oxaliplatin regimen were followed routinely in patients with large and poorly differentiated hepatocellular carcinoma after LT in our centre. The patient is 
presently alive and disease-free for three years after the third operation. We hypothesize some potential beneficial elements, such as complete surgical removal, unusual sensitivity to adjuvant therapy [13], endocrine influence [14], allergic reaction [15], and interference with nutrition of the tumor [16]. We believe severe follow up is necessary for the patient in future.

\section{Conclusion}

In conclusion, this is an interesting report on a somehow indolent metastatic spread of HCC. It should be considered that metachronous metastatic resectable disease, with no data of recurrence at the primary site in an operable patient, is an indication to perform a surgical resection.

\section{Consent}

Written informed consent was obtained from the patient for publication of this case report and accompanying images. A copy of the written consent is available for review by the Editor-in-Chief of this journal.

\section{Abbreviations}

LT: Liver transplantation; HCC: hepatocellular carcinoma; AFP: serum alphafetoprotein.

\section{Authors' contributions}

SWC, SW, WDL, and SY participated in the admission and the care of this patient. All the authors participated in the conception, the design, data collection and interpretation, manuscript preparation and literature search. All authors have read and approved the final manuscript.

\section{Competing interests}

The authors declare that they have no competing interests.

Received: 14 June 2011 Accepted: 28 November 2011

Published: 28 November 2011

\section{References}

1. Rubio E, González J, Jimenéz M, Lucena JL, Gimenez L, Martinez Arrieta F, Cuervas-Mons V, Turrión VS: Right adrenal metastases of hepatocarcinoma after liver transplantation: case report and literature review. Transplant Proc 2009, 41(3):1067-1069.

2. Mourad YA, Khalifeh M, Taher A, Tawil A, Shamseddine A: Hepatocellular carcinoma with isolated left adrenal metastasis following liver transplantation. Ann Saudi Med 2004, 24(1):65-67.

3. Castroagudín JF, González-Quintela A, Martínez J, Tomé S, Forteza J, Varo E: Bilateral adrenal metastases from hepatocellular carcinoma after liver transplantation. Hepatogastroenterology 2002, 49(43):249-251.

4. Ferris JV, Baron RL, Marsh JW Jr, Oliver JH, Carr Bl, Dodd GD: Recurrent hepatocellular carcinoma after liver transplantation: spectrum of CT findings and recurrence patterns. Radiology 1996, 198(1):233-238.

5. Uka K, Aikata H, Takaki S, Shirakawa H, Jeong SC, Yamashina K, Hiramatsu A, Kodama H, Takahashi S, Chayama K: Clinical features and prognosis of patients with extrahepatic metastases from hepatocellular carcinoma. World J Gastroenterol 2007, 13(3):414-420.

6. Pandey D, Tan KC: Surgical resection of adrenal metastasis from primary liver tumors: a report of two cases. Hepatobiliary Pancreat Dis Int 2008, 7(4):440-442.

7. Park JS, Yoon DS, Kim KS, Choi JS, Lee WJ, Chi HS, Kim BR: What is the best treatment modality for adrenal metastasis from hepatocellular carcinoma? J Surg Oncol 2007, 96(1):32-36.
8. Rousselet JM, Sebbag H, Henry L, Paliard P, Partensky C: Adrenal metastases of hepatocellular carcinoma. Therapeutic options. Chirurgie 1998, 123(3):280-286.

9. Nakahashi C, Kinoshita T, Konishi M, Nakagohri T, Inoue K, Oda T, Yoshida J, Hasebe T, Ochiai A: Long-term survival achieved by repeated resections of metachronous pulmonary and adrenal metastases of alphafetoprotein-producing gastric cancer: report of a case. Surg Today 2004, 34(9):784-787.

10. Lee JO, Kim DY, Lim JH, Seo MD, Yi HG, Oh DY, Im SA, Kim TY, Bang YJ: Palliative chemotherapy for patients with recurrent hepatocellular carcinoma after liver transplantation. J Gastroenterol Hepatol 2009, 24(5):800-805

11. Boige V, Raoul JL, Pignon JP, Bouché O, Blanc JF, Dahan L, Jouve JL, Dupouy N, Ducreux M, Fédération Francophone de Cancérologie Digestive: Multicentre phase II trial of capecitabine plus oxaliplatin (XELOX) in patients with advanced hepatocellular carcinoma: FFCD 03-03 trial. $\mathrm{Br}$ Cancer 2007, 97(7):862-867.

12. Berretta M, Lleshi A, Di Benedetto F, Bearz A, Spina M, Tirelli U: Oxaliplatin and capecitabine (Xelox) in association with highly active antiretroviral therapy in advanced hepatocarcinoma HIV/HCV-infected patients. Ann Oncol 2006, 17(7):1176-1177.

13. Shimoda M, Ghobrial RM, Carmody IC, Anselmo DM, Farmer DG, Yersiz H, Chen P, Dawson S, Durazo F, Han S, Goldstein LI, Saab S, Hiatt J, Busuttil RW: Predictors of survival after liver transplantation for hepatocellular carcinoma associated with Hepatitis C. Liver Transp/ 2004, 10(12):1478-1486.

14. Ringe B, Pichlmayr R: Liver transplantation for malignant tumours. Baillieres Clin Gastroenterol 1989, 3(4):787-797.

15. Kawaoka T, Aikata H, Katamura Y, Takaki S, Waki K, Hiramatsu A, Takahashi S, Hieda M, Kakizawa H, Chayama K: Hypersensitivity reactions to transcatheter chemoembolization with cisplatin and Lipiodol suspension for unresectable hepatocellular carcinoma. J Vasc Interv Radiol 2010, 21(8):1219-1225.

16. Seitz HK, Stickel F: Risk factors and mechanisms of hepatocarcinogenesis with special emphasis on alcohol and oxidative stress. Biol Chem 2006, 387(4):349-360.

doi:10.1186/1477-7819-9-156

Cite this article as: Chen et al.: Metachronous pulmonary and adrenal metastases after liver transplantation for hepatocarcinoma. World Journal of Surgical Oncology 2011 9:156.

\section{Submit your next manuscript to BioMed Central and take full advantage of:}

- Convenient online submission

- Thorough peer review

- No space constraints or color figure charges

- Immediate publication on acceptance

- Inclusion in PubMed, CAS, Scopus and Google Scholar

- Research which is freely available for redistribution 